"نشريه علوم زراعى ايران"

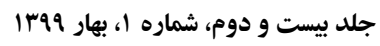

مقاله : بزوهشى

اثر تنش خشكى بر القاى خواب تابستانه و تسهيم ماده خشك در اكوتيبهاى يونجه (Medicago sativa L.) Effect of drought stress on the induction of summer dormancy and dry matter partitioning in alfalfa (Medicago sativa L.) ecotypes

سيدمحمدعلى مفيد يان' '، جعفر احمدى 'و على مقدمّ

جצكيده

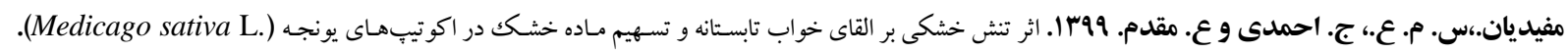

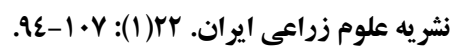

ارزيابع يتانسيل اكوتيٍٍ هاى يونجه از نظر نحوه تسهيم زيست توده به بخشهاى قابل برداشت و غيـر قابـل برداشـت در شـرايط

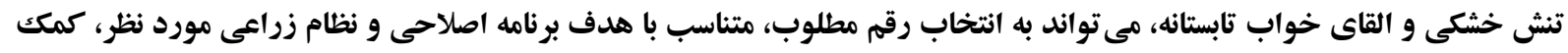

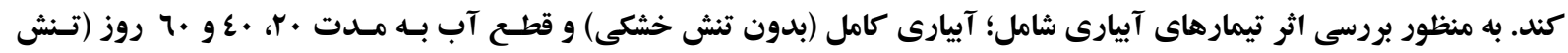

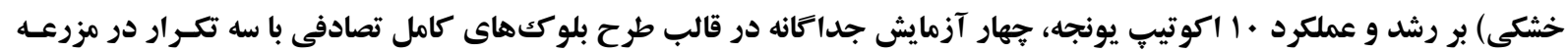

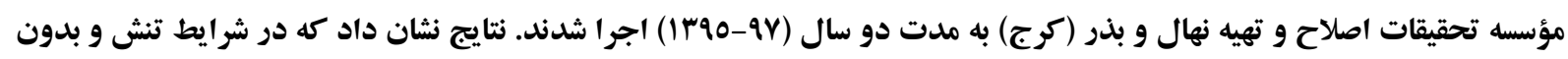

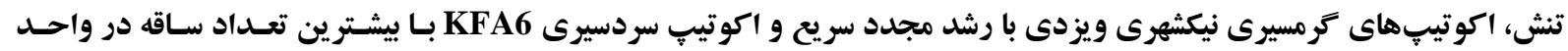

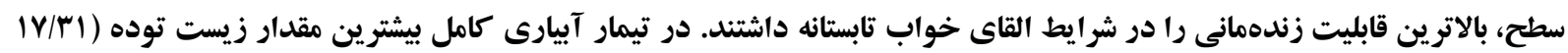

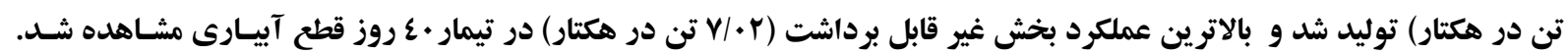

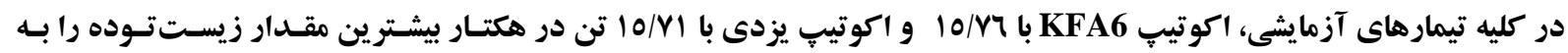

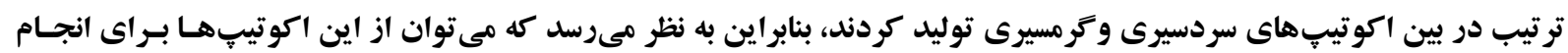
تلاقى در كروه خود استفاده كرد. از نظر نحوه تسهيم زيست توده، اكوتيبهاي

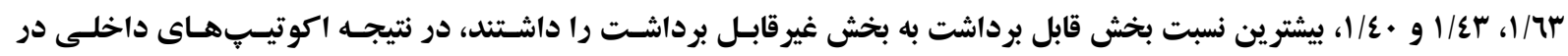

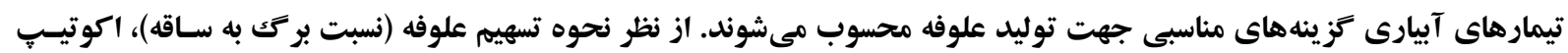

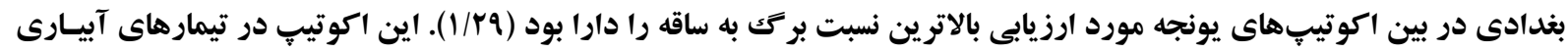

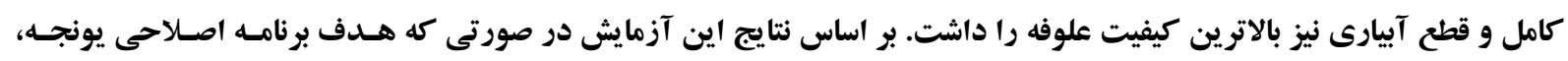

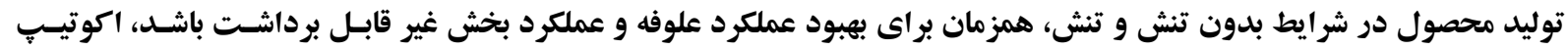

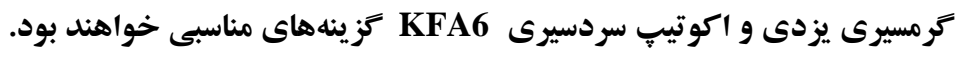

وازههاى كليدى: آبيارى، رشد مجدد، عملكرد علوفه، نسبت بر كى به ساقه و يونجه.

\footnotetext{
اين مقاله مستخرج از رساله دكترى نخارنده اول مى باشد.

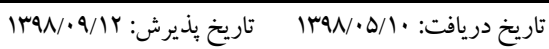

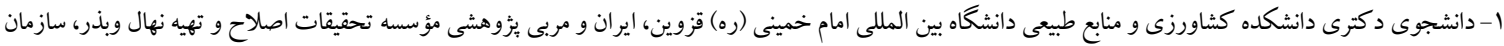

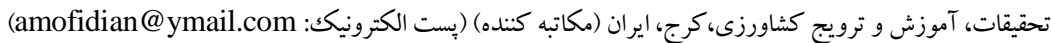

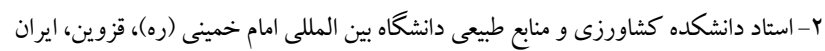

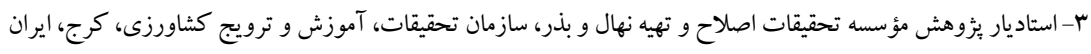


يونجـهـ بهترين گيـاه بـراى قطع آبيـارى در طسول دوره

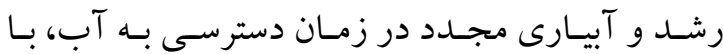

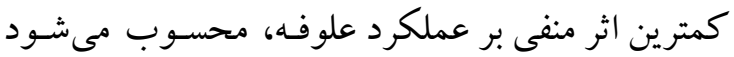
(Schonhorst et al., 1963)

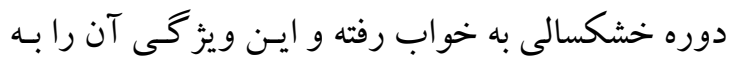

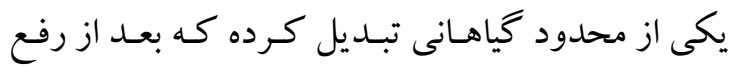

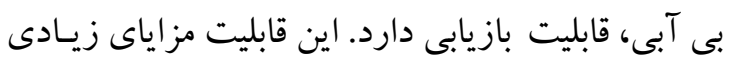

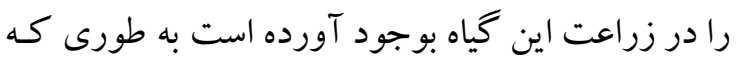
كياهان داراى خواب، تحمل بالاترى نسبت به تنش زوراعـاى

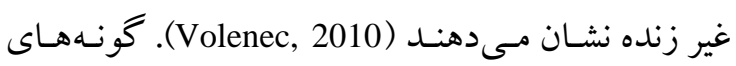

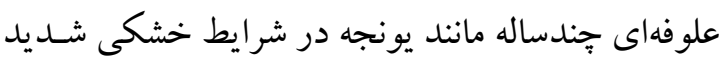

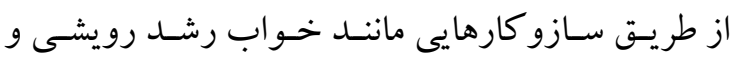

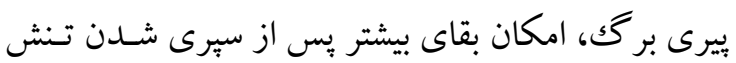

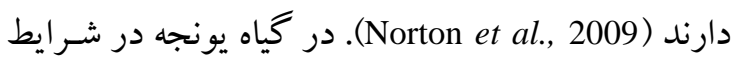

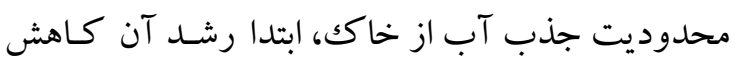
يافته و سيّس متوقـف مىشـود (Erice et al., 2010). در

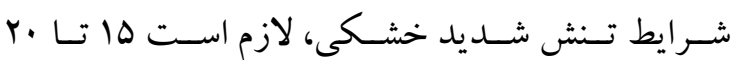

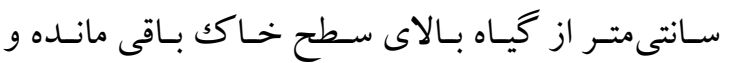

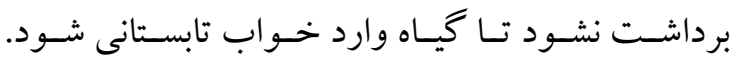

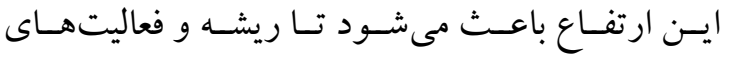

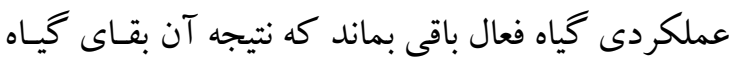

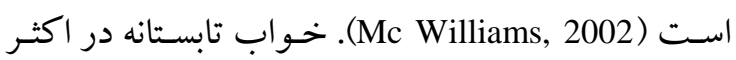

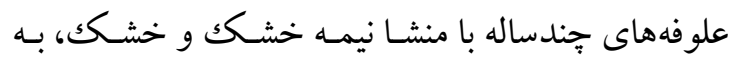

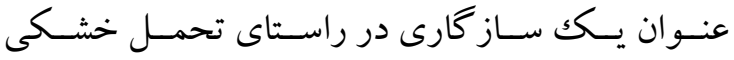
محسـوب مى شــود (Norton et al., 2009). نتــايج تحقيقات نشـان داده اسـت كـه بـا در نظر كـرفتن تنـوع

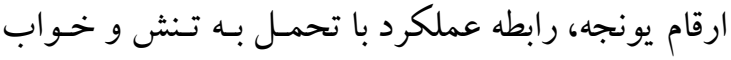

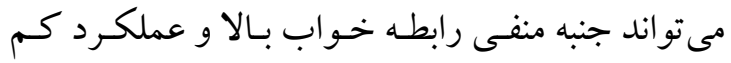

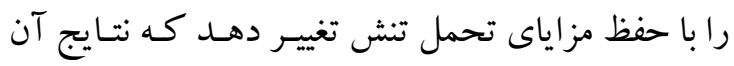

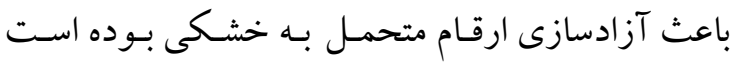

.(Brouwer et al., 2000; Brummer et al., 2000) هـدف از اجــراى ايـن بــزوهش شناسـايى روابـط

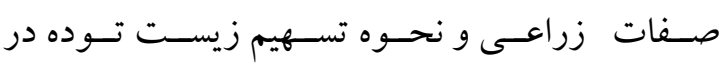

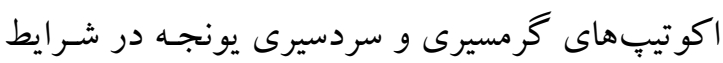

\section{مقدمه}

افزايش جمعيت جهان و افز ايش نيـاز غـذايى مـردم

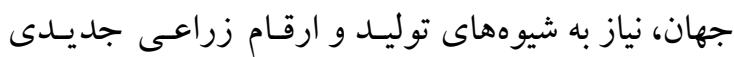

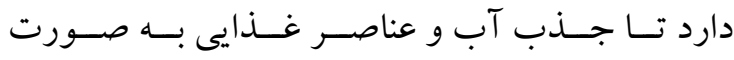
كار آمـدترى انجـام شـود(Paez-Garcia et al., 2015).

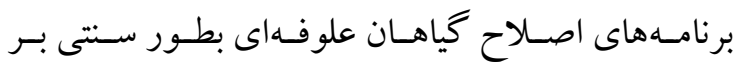

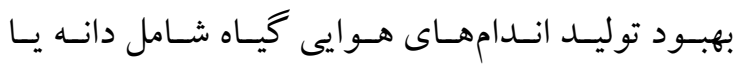

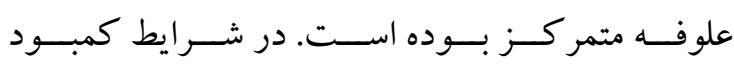

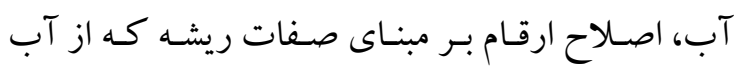

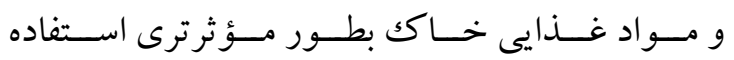
(Hufnagel et al., 2014; شـود، اهميـت بيشترى دارئ Kell, 2011; Uga et al., 2013)

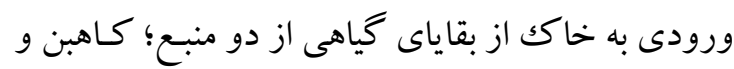

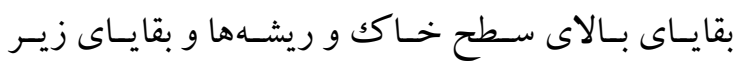

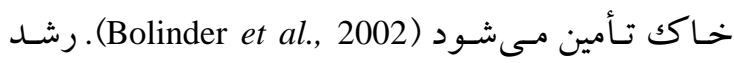
سلولهاى كياهى نسبت بـه كمبـود آب بسيار حسـاس

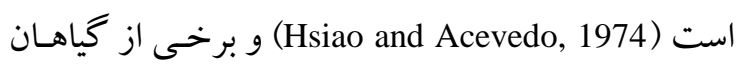

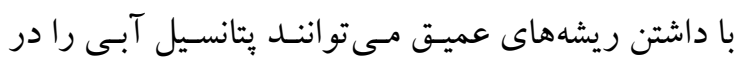
حد بالايى حفظ كنند. در اين كياهان در شـرايط تسنش، ونس،

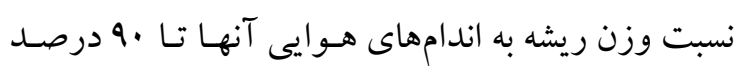

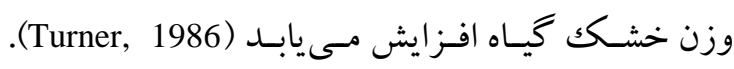

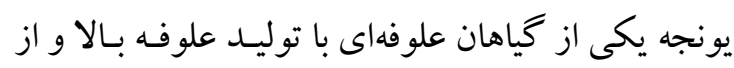

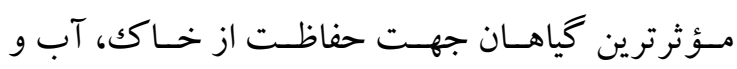

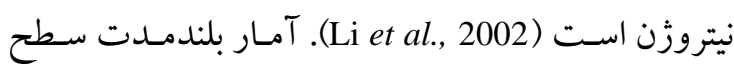
زير كشت يونجه در ايران نشان مىدهد كه سطح كشت

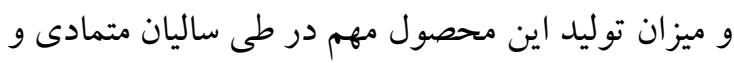

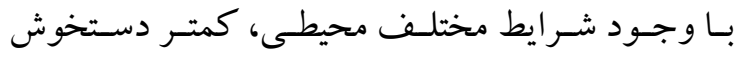

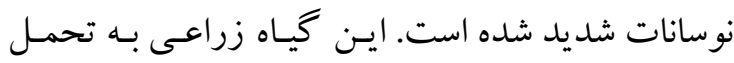
خشكى مشهور است، زيرا مى تواند بوسيله سيستم ريشه-

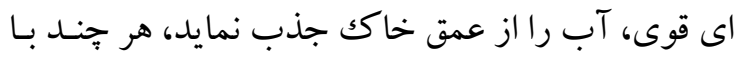

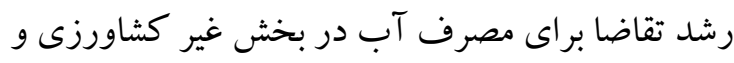

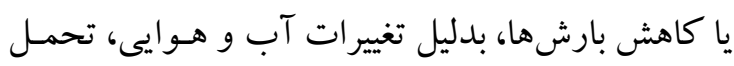

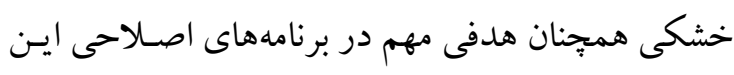
گيـاه قلمـاد مسى شـود (Annicchiarico et al., 2013). 


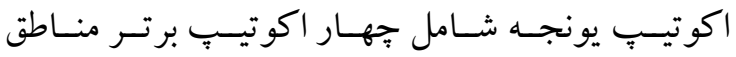
قطع آبيارى بود. سردسيرى از توده همدانى و قرهيونجه و جهار اكوتيسب

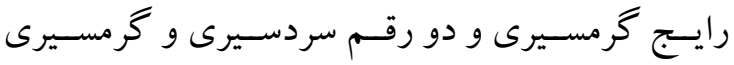
مواد و روشها

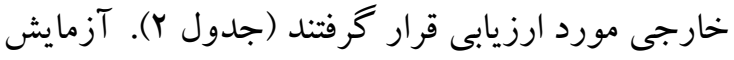

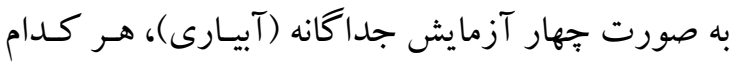
در قالب طرح بلوككهاى كامـل تصـادفى بـا سـه تكـرار

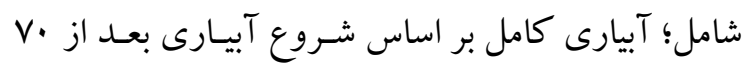
ميلى متر تبخير از سطح تشـتك تبخيـر كـلاس A (بـدون

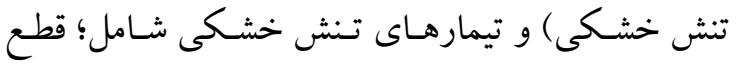

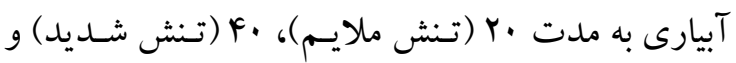

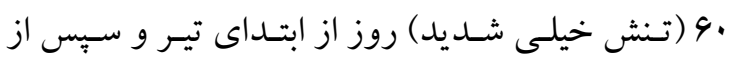

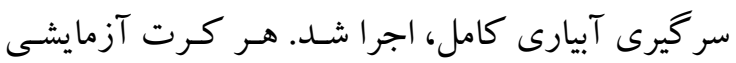

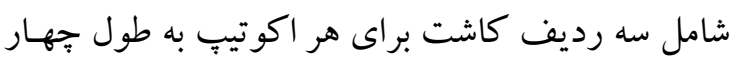

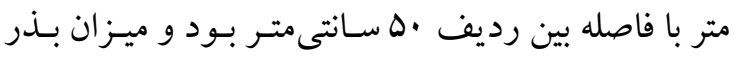

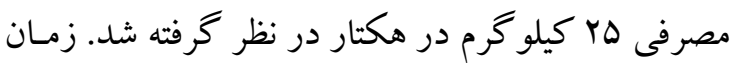

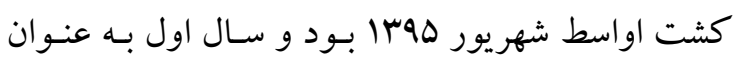

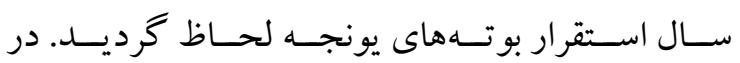

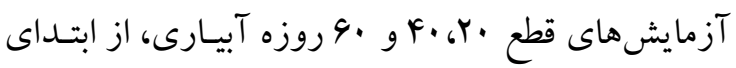

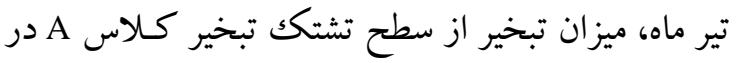

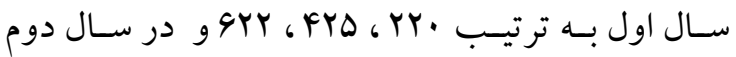

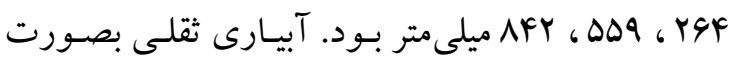
جوى و يشته و با استفاده از لولههاى يلى اتيلنى و بطور

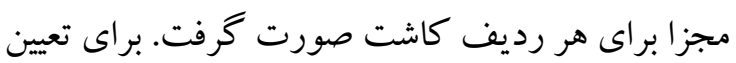

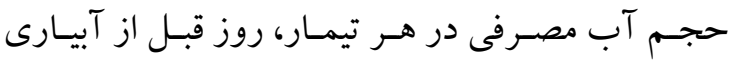
نمونه بردارى از خاكك انجام شد و درصد رطوبت وزنى

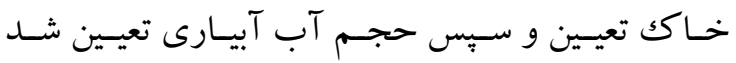

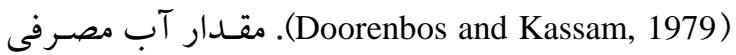
با استفاده از كنتور كه در ابتداى فلكه اصلى قرار داده

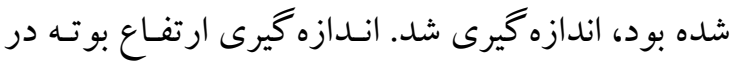

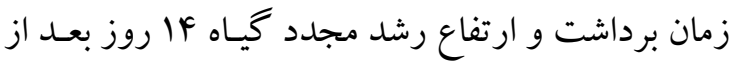

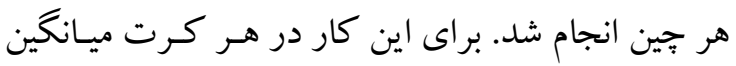

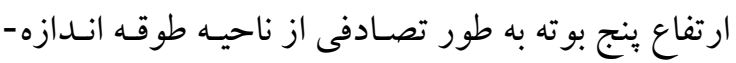

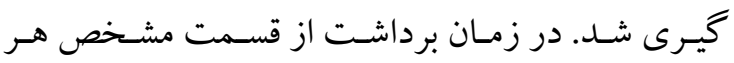

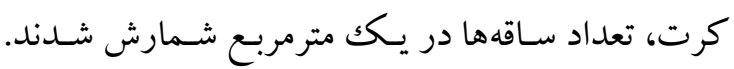

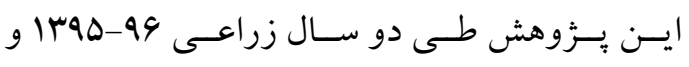

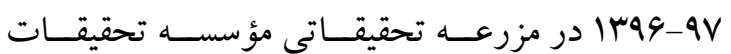

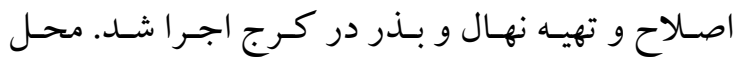

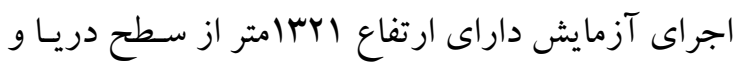

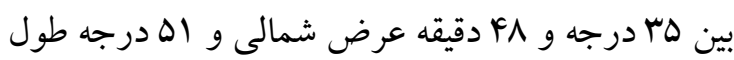
شرقى واقع شده است. اطلاعات هو اشناسى محل اجراى آزمايش طى دو سال در جدول الارائه شـده اسـت. بـر

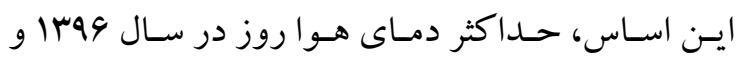

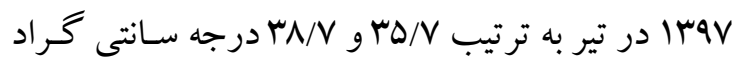

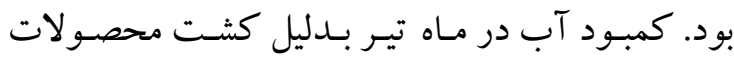
تابستانه و رقيب، شديدتر است. با اين ترتيب آزمايش بـا ديا

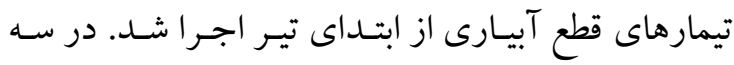

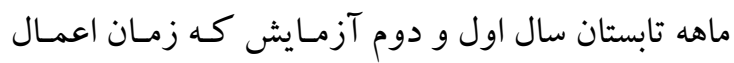
تيمارهاى قطع آبيارى بود، ميانخين حداقل دما به ترتيب

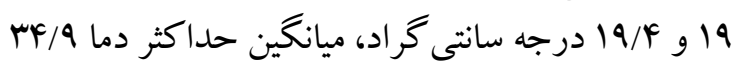

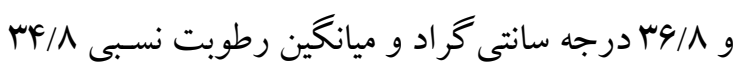

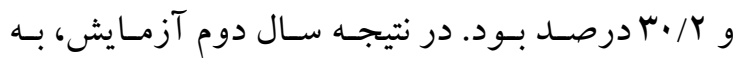
مراتب گرم و خشكك تر از سال اول بود. بر اساس نتسايج

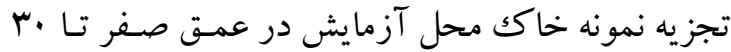

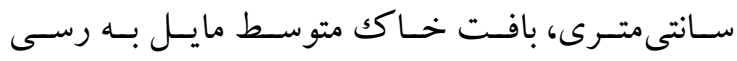

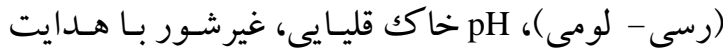

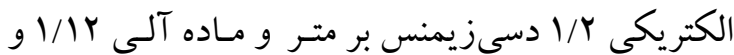

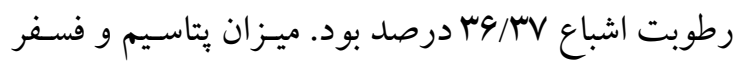

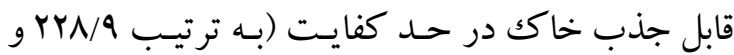

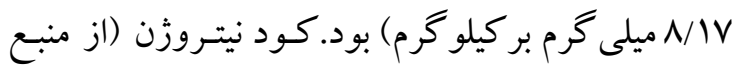

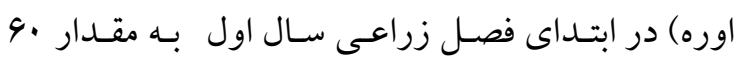

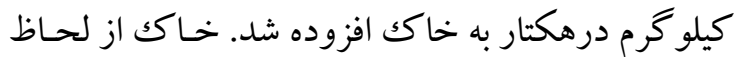

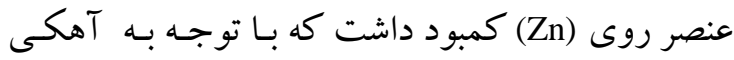
بـودن و pH قليـايى آن، كمبـود عناصـر ميكـرو محتمـل

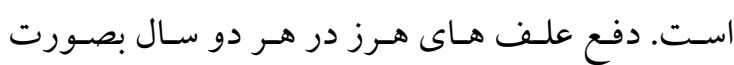

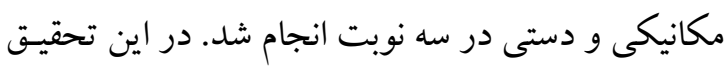




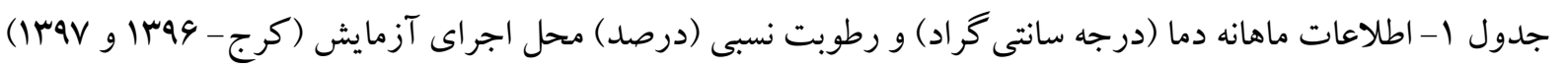

Table 1. Monthly temperature $\left({ }^{\circ} \mathrm{C}\right)$ and relative humidity (\%) of the experiment site (Karaj- 2017 and 2018)

\begin{tabular}{|c|c|c|c|c|c|c|c|c|c|c|c|c|c|}
\hline \multirow[b]{2}{*}{ Month } & \multirow[b]{2}{*}{ ماه } & \multicolumn{6}{|c|}{$\begin{array}{r}1499 \\
2017 \\
\end{array}$} & \multicolumn{6}{|c|}{$\begin{array}{r}\text { Irqv } \\
2018 \\
\end{array}$} \\
\hline & & $\begin{array}{c}\text { كمينه دما } \\
T_{\max } \\
\end{array}$ & $\begin{array}{c}\text { بيشينه } \\
T_{\text {min }} \\
\end{array}$ & $\begin{array}{c}\text { دماى متوسط } \\
T_{m} \\
\end{array}$ & $\begin{array}{c}\text { كمينه رطويت } \\
H_{\min } \\
\end{array}$ & $\begin{array}{c}\text { بيشنه رطوبت } \\
H_{\max } \\
\end{array}$ & $\begin{array}{c}\text { متوسط رطويت } \\
H_{m} \\
\end{array}$ & $\begin{array}{c}\text { كمينه دما } \\
T_{\max } \\
\end{array}$ & $\begin{array}{c}\text { بيشينه } \\
T_{\min } \\
\end{array}$ & $\begin{array}{c}\text { دماى متوسط } \\
T_{m} \\
\end{array}$ & $\begin{array}{c}\text { كمينه رطويت } \\
H_{\min } \\
\end{array}$ & $\begin{array}{c}\text { بيشينه رطويت } \\
H_{\max } \\
\end{array}$ & $\begin{array}{c}\text { متوسط رطويت } \\
\mathrm{H}_{\mathrm{m}}\end{array}$ \\
\hline Mar 21- Apr 20 & ا فروردين - الب فروردين & 7.8 & 17.8 & 12.8 & 37.0 & 73.1 & 55.0 & 7.4 & 22.0 & 14.4 & 23.8 & 66.2 & 43.2 \\
\hline Apr 21- May 21 & | ارديبهش- ابrارديبهشت & 12.8 & 26.6 & 19.5 & 28.5 & 71.8 & 50.1 & 10.4 & 23.7 & 16.4 & 32.6 & 79.5 & 56.1 \\
\hline May 22- Jun 21 & اخرداد - الب خرداد & 16.4 & 33.0 & 25.3 & 12.8 & 53.8 & 33.3 & 15.3 & 32.1 & 23.3 & 19.0 & 70.1 & 43.5 \\
\hline Jun 22- Jul 22 & ا تير - اب تير & 19.6 & 35.7 & 27.8 & 14.9 & 55.4 & 35.1 & 20.6 & 38.7 & 29.8 & 12.5 & 45.5 & 25.6 \\
\hline Jul 23- Aug 22 & ا مرداد- الب مرداد & 19.9 & 35.9 & 28.4 & 15.2 & 57.1 & 36.1 & 20.9 & 37.7 & 29.2 & 14.6 & 53.8 & 30.7 \\
\hline Aug 23-Sep 22 & اشهريور - ابسشهريور & 17.6 & 33.2 & 25.4 & 15.2 & 51.5 & 33.3 & 16.6 & 34.0 & 24.8 & 15.8 & 59.8 & 34.3 \\
\hline Average of spring & ميانكين بهار & 12.3 & 25.8 & 19.2 & 26.1 & 66.2 & 46.1 & 11.0 & 25.9 & 18.0 & 25.1 & 71.9 & 47.6 \\
\hline Average of summer & ميانگين تابستان & 19.0 & 34.9 & 27.2 & 15.1 & 54.7 & 34.8 & 19.4 & 36.8 & 27.9 & 14.3 & 53.0 & 30.2 \\
\hline Average of year & ميانگين سال & 15.7 & 30.4 & 23.2 & 20.6 & 60.5 & 40.5 & 15.2 & 31.4 & 23.0 & 19.7 & 62.5 & 38.9 \\
\hline
\end{tabular}

جدول r- اسامى و منشا اكو تيبهاى يونجه مورد ارزيابى

Table 2. Name and the origin of alfalfa ecotypes used in the experiment

\begin{tabular}{|c|c|c|c|c|c|c|c|}
\hline كد & Ecotype & اكوتيبِ & Origin* & كد & Ecotype & اكوتيبِ & Origin منشاء \\
\hline G1 & Bami & & ومى، خرمسيرى L-W & G6 & KFA6 & قرميونجه & L-C \\
\hline G2 & Yazdi & 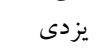 & L-W بومى، گرمسيرى & G7 & KFA13 & قرهيونجه & بومى، سردسيرى \\
\hline G3 & Nikshahri & نيكشهرى & L-W بومي، خرمسيرى & G8 & Laklak & لك لكى، همدان & بومي، سردسيرى \\
\hline G4 & Baghdadi & بغدادى & L-W بومى، گرمسيرى & G9 & Mesasersa & مساسر سا & خارجى، گرمسيرى E-W \\
\hline G5 & KFA17 & همداني & L-C بومى، سردسيرى & G10 & Diabloverde & ي ديابلو رده & خارجى، سردسيرى E-C \\
\hline
\end{tabular}

'L: Landrace; E: Exotic; C: Cold region; W: Warm region 
عملكرد ريشـه در سـطح بـنج درصــ معنسىدار بـود، بـهـ

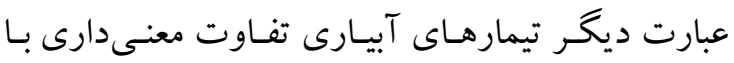

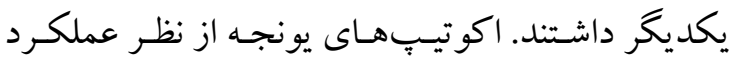

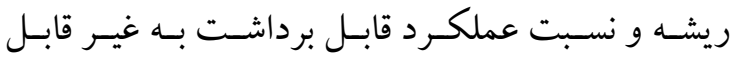

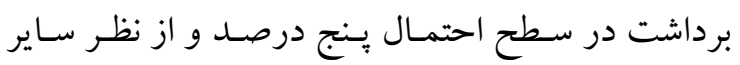

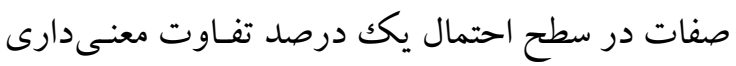

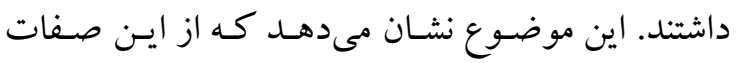

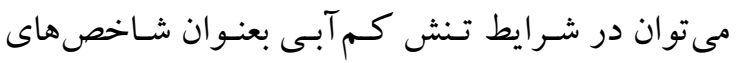

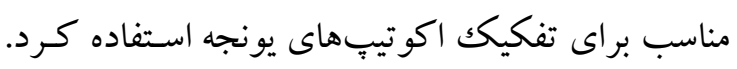

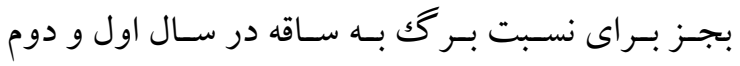

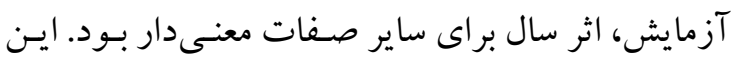

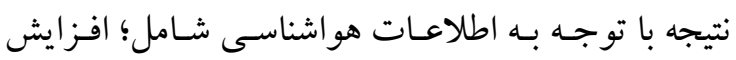

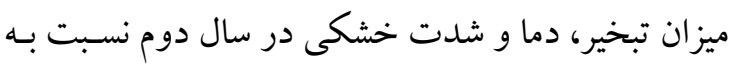

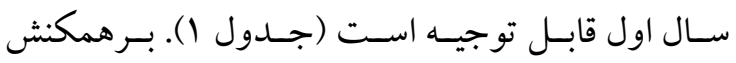
اكو تيب در آبيارى بـراى صفت تعـداد سـاقه در سـطح

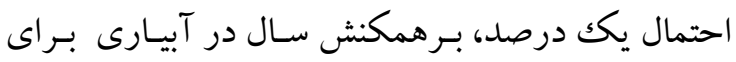

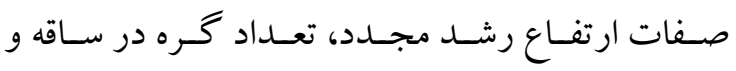

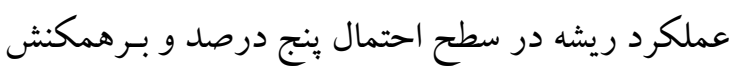
سال در اكوتيب براى زيست توده، ارتفاع بوتـه، ارتفـاع

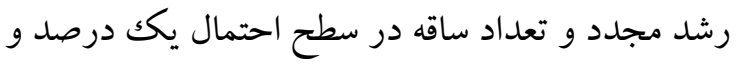

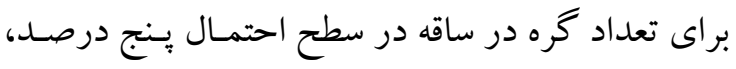

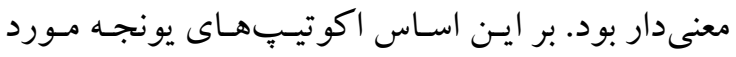
ارزيابى از نظر تعـداد سـاقه در تيمارهـاى آبيـارى و در ئر

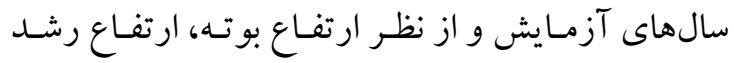

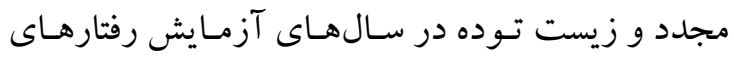
متفاوتى داشتند. اندازهيرى ارتفاع رشد مجدد بوته در انتهاى فصـل رشـــ معيـار مهمـى در طبقـهبنـدى ارقـام يونجـه بشـمار

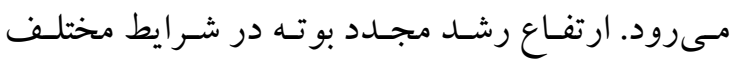

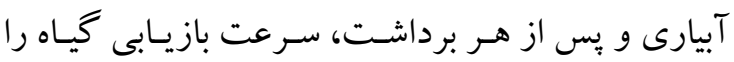

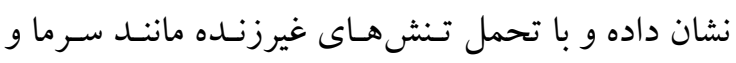
خشكى در ارتبـاط است (Brummer et al., 2000). در ور اين بثزوهش ميانخين ارتفاع رشد مجدد بو تههاى يونجسه

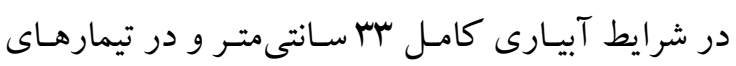

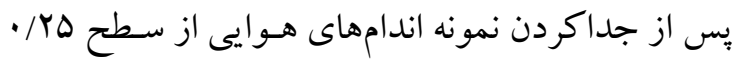
مترمربع از هركـرت و تفكيكك بـرك و سـاقه و تـوزين

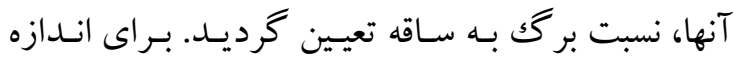
كيرى عملكرد قسمت غيرقابل برداشت شـامل؛ ريشهه و

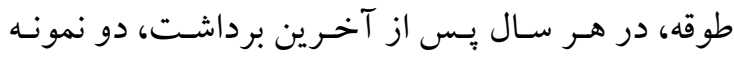

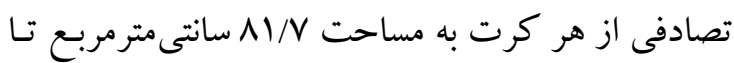

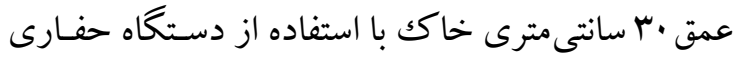

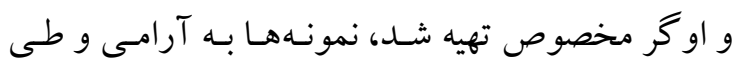

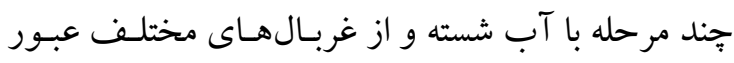
داده شدند تا تنها خاكك آن جدا شود. نمونههاى ريشه و و

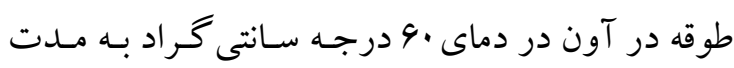

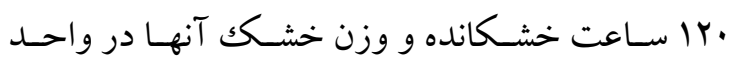
سطح محاسبه شد (Shewmaker and Thaemert, 2004).

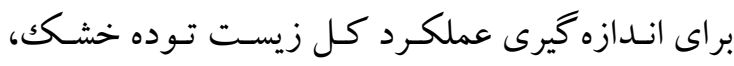

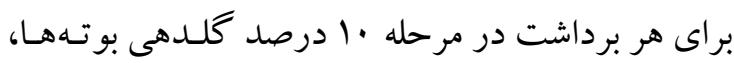

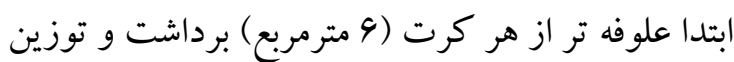

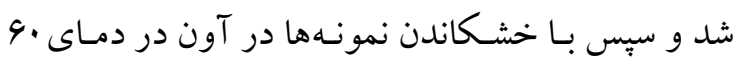
درجه سانتى گر اد به مدت VY سـاعت، مجمسوع سـاليانه

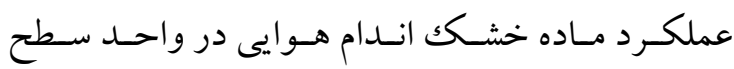

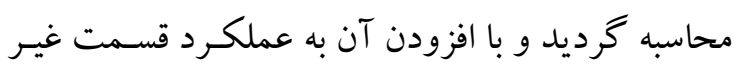

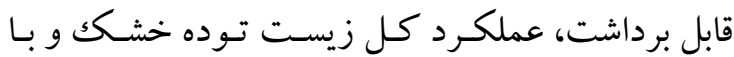

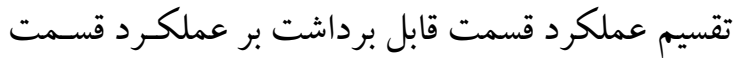
غيـر قابـل برداشـت، نسـبت عملكـرد قابـل برداشـت بـهـ

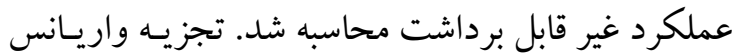

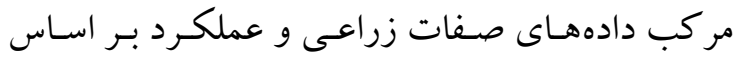

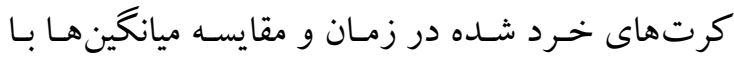

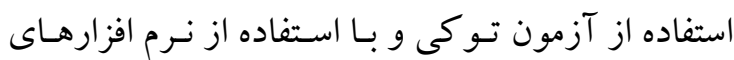
EXCEL 2016

\section{نتايج و بحث}

نتايج تجزيـه واريـانس نشـان داد كـه اثر تيمارهـاى آبيارى براى كليه صفات زيست توده و نسبت عملكـرد

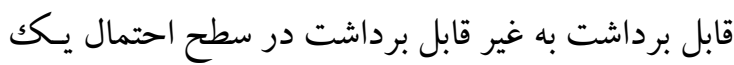

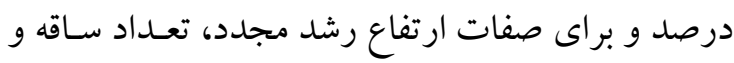


قطع آبيارى Y سانتىمتر بود (جدول r). دليـل نزديكك الف). ميـانگين تعـداد سـاقهها در تيمارهـاى قطـع آبيـارى

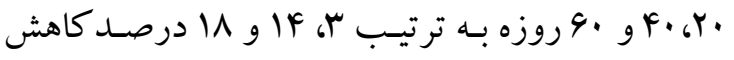

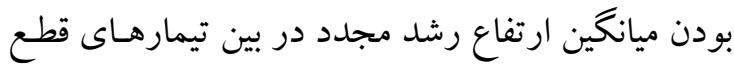

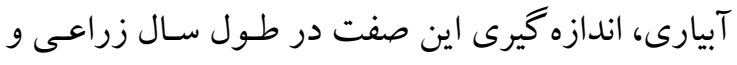
يافت (شكل ا-ب). در سال دوم آزمايش تعداد سـاقهها

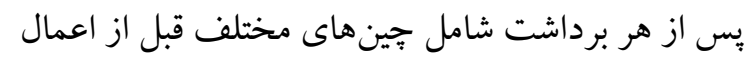

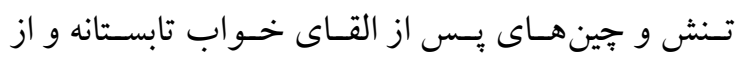
سر گيرى آبيارى بود.

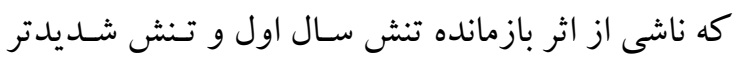

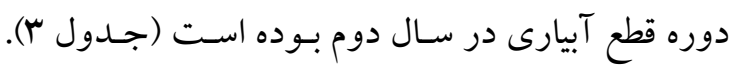

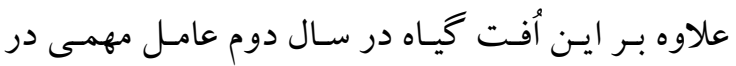
كاهش تعـداد سـاقهها در يونجـه اسـت (Leach, 1970).

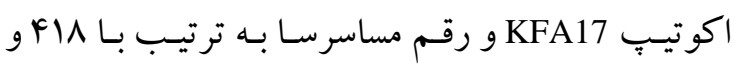

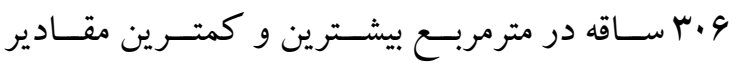

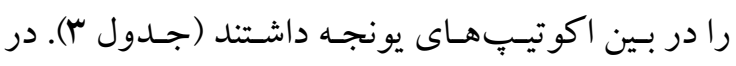

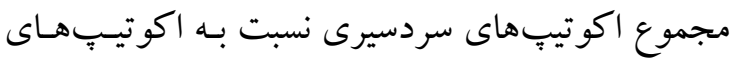

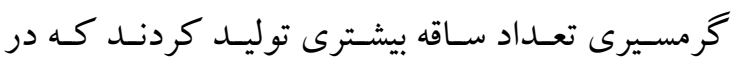

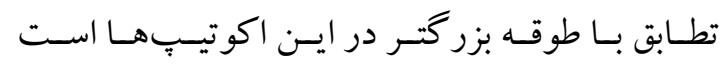
(Marquez-Ortiz, et al., 1996)

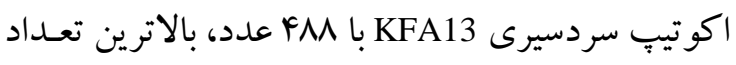

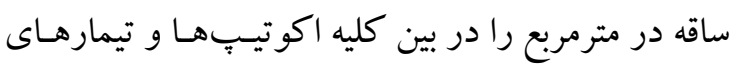

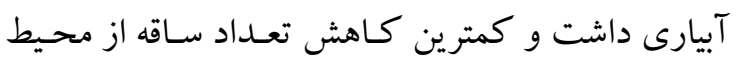
بدون تنش تا تنش خيلى شديد (قطع •و روزه آبيارى)

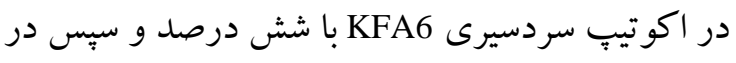

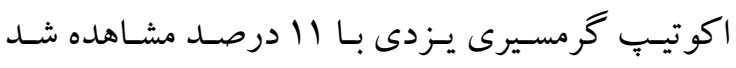

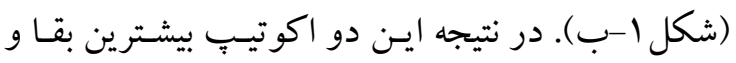

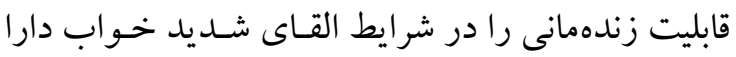

نسـبت بـرك گكسه سـاقه از عو امـل مهـم و مـوثر در

كيفيت علوفه يونجـه محسـوب مىشـود (Moore and

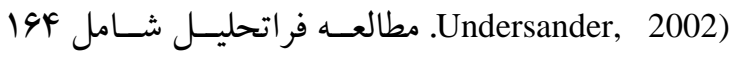
يزوهش انجام شده روى نحسوه تسهيم زيست تـوده در

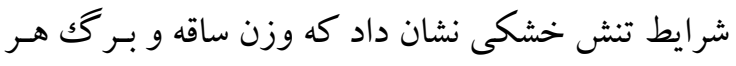

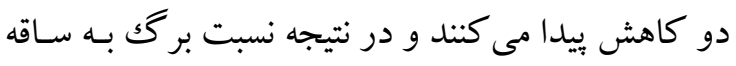

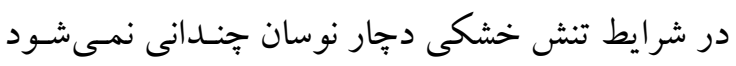

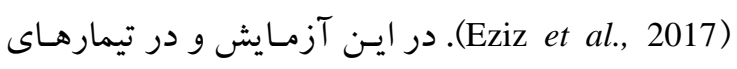

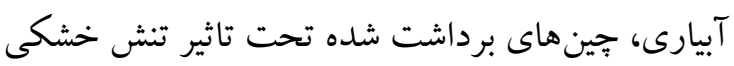




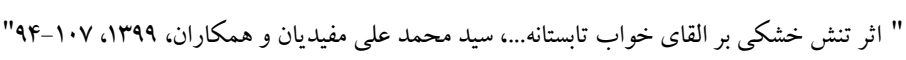

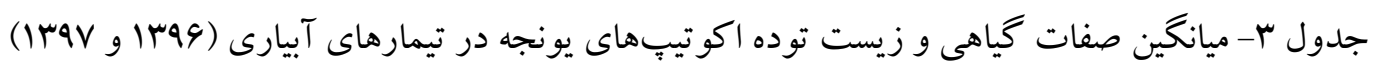

Table 3. Mean comparisons of plant traits and biomass of alfalfa ecotypes in irrigation treatments (2017 and 2018) وزن خشك ريشه بخش قابل برداشت:غيرقابل برداشت Plant height $(\mathrm{cm}) \quad$ Regrowth height $(\mathrm{cm}) \quad$ No. Stem $\quad$ No. Node $\quad$ Leaf : Stem $\quad$ Biomass $\left(\mathrm{t}^{-1} \mathrm{~h}^{-1}\right) \quad$ Root dry weight $\left(\mathrm{t}^{-1} \mathrm{~h}^{-1}\right) \quad$ Harvestable:Non-Harvestable

\begin{tabular}{|c|c|c|c|c|c|c|c|c|c|}
\hline & & 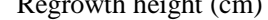 & (1) & 10. Nour the & Ste & nass (t.F & & \\
\hline Irrigation treatments & تيمارهاى آبيارى & & & & & & & & \\
\hline Full irrigation & آبيارى كامل & $51 \mathrm{a}$ & $33 \mathrm{a}$ & $404 \mathrm{a}$ & $8.9 \mathrm{a}$ & $1.09 \mathrm{a}$ & $17.31 \mathrm{a}$ & $6.58 \mathrm{~b}$ & $1.75 \mathrm{a}$ \\
\hline Irrigation withhold; 20 days & r. بروز قطع آبيارى : & $50 \mathrm{a}$ & $28 \mathrm{~b}$ & $391 \mathrm{a}$ & $9.1 \mathrm{a}$ & $1.12 \mathrm{a}$ & $15.10 \mathrm{~b}$ & $6.11 \mathrm{~b}$ & $1.52 \mathrm{~b}$ \\
\hline Irrigation withhold; 40 days & 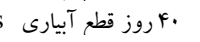 & $50 \mathrm{a}$ & $28 \mathrm{~b}$ & $344 b$ & $8.7 \mathrm{a}$ & $1.09 \mathrm{a}$ & $13.79 \mathrm{bc}$ & $7.02 \mathrm{a}$ & $1.10 \mathrm{c}$ \\
\hline Irrigation withhold; 60 days & . وروز قطع آبيارى & $51 \mathrm{a}$ & $28 \mathrm{~b}$ & $333 \mathrm{~b}$ & $8.6 \mathrm{a}$ & $1.11 \mathrm{a}$ & $13.06 \mathrm{c}$ & $6.91 \mathrm{a}$ & $1.02 \mathrm{c}$ \\
\hline Year & سال & & & & & & & & \\
\hline 2017 & 1 irag & $53 \mathrm{a}$ & $28 \mathrm{~b}$ & $406 \mathrm{a}$ & $9.0 \mathrm{a}$ & $1.09 \mathrm{a}$ & $16.19 \mathrm{a}$ & $6.74 \mathrm{a}$ & $1.45 \mathrm{a}$ \\
\hline 2018 & irav & $48 \mathrm{~b}$ & $31 \mathrm{a}$ & $330 \mathrm{~b}$ & $8.7 \mathrm{~b}$ & $1.12 \mathrm{a}$ & $13.54 \mathrm{~b}$ & $6.68 \mathrm{a}$ & $1.25 \mathrm{~b}$ \\
\hline Alfalfa ecotypes & اكوتيبهاي يونجه & & & & & & & & \\
\hline Bami & بمى & $52 \mathrm{ab}$ & $31 \mathrm{c}$ & $361 \mathrm{~b}$ & $8.8 \mathrm{~b}-\mathrm{d}$ & $1.06 \mathrm{~cd}$ & $15.35 \mathrm{ab}$ & $7.11 \mathrm{ab}$ & $1.27 \mathrm{ab}$ \\
\hline Yazdi & 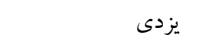 & $53 \mathrm{a}$ & $36 \mathrm{a}$ & $350 \mathrm{bc}$ & $9.3 \mathrm{ab}$ & $1.15 \mathrm{bc}$ & $15.71 \mathrm{a}$ & $6.86 \mathrm{ab}$ & $1.40 \mathrm{ab}$ \\
\hline Nikshahri & نيكشهرى & $51 \mathrm{ab}$ & $38 \mathrm{a}$ & $322 \mathrm{~cd}$ & $9.3 \mathrm{ab}$ & $1.27 \mathrm{a}$ & $14.04 \mathrm{bc}$ & $6.74 a b$ & $1.19 \mathrm{~b}$ \\
\hline Baghdadi & بغدادى & $51 \mathrm{ab}$ & $33 b$ & $337 b-d$ & $9.1 \mathrm{a}-\mathrm{c}$ & $1.29 \mathrm{a}$ & $14.64 \mathrm{bc}$ & $6.46 \mathrm{ab}$ & $1.34 \mathrm{ab}$ \\
\hline KFA17 & & $51 \mathrm{ab}$ & $25 \mathrm{e}$ & $418 \mathrm{a}$ & $8.5 \mathrm{de}$ & $0.99 \mathrm{~d}$ & $14.74 \mathrm{bc}$ & $6.10 \mathrm{ab}$ & $1.63 \mathrm{a}$ \\
\hline KFA6 & & $52 \mathrm{ab}$ & $27 \mathrm{~d}$ & $414 a$ & $8.5 \mathrm{de}$ & $0.98 \mathrm{~d}$ & $15.76 \mathrm{a}$ & 6.84ab & $1.43 \mathrm{ab}$ \\
\hline KFA13 & & $50 \mathrm{~b}$ & 26de & $415 a$ & $8.5 \mathrm{de}$ & $0.98 \mathrm{~d}$ & $15.44 \mathrm{ab}$ & 7.38a & $1.17 \mathrm{~b}$ \\
\hline Laklak & لك لك & $51 \mathrm{ab}$ & 26de & $414 a$ & $8.7 \mathrm{~cd}$ & $0.98 \mathrm{~d}$ & $14.94 \mathrm{bc}$ & $6.46 \mathrm{ab}$ & $1.39 \mathrm{ab}$ \\
\hline Mesasersa & مساسرسا & $53 \mathrm{a}$ & $31 \mathrm{c}$ & $306 \mathrm{~d}$ & $9.4 \mathrm{a}$ & $1.18 \mathrm{ab}$ & $15.59 \mathrm{a}$ & $7.24 \mathrm{a}$ & $1.30 \mathrm{ab}$ \\
\hline Diabloverde & ديابلورده & $39 \mathrm{c}$ & $19 \mathrm{f}$ & $344 \mathrm{bc}$ & $8.1 \mathrm{e}$ & $1.16 \mathrm{bc}$ & $11.95 \mathrm{c}$ & $5.38 \mathrm{~b}$ & $1.26 \mathrm{ab}$ \\
\hline
\end{tabular}

Means in each column followed by similar letter(s) are not significantly different at 5\% probability levels, using Tukey's test

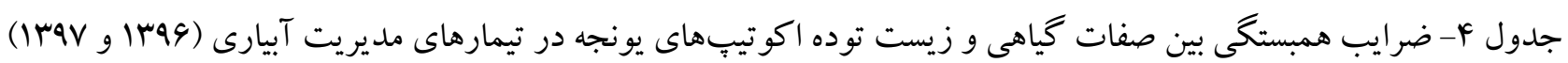

Table 4. Correlation coefficients between plant traits and biomass of alfalfa ecotypes in irrigation treatments (2017 and 2018 )

\begin{tabular}{|c|c|c|c|c|c|c|c|c|}
\hline Plant traits & صفات گَاهي & $\begin{array}{c}\text { ارتفاع رشد مجدد } \\
\text { Regrowth height }\end{array}$ & $\begin{array}{c}\text { تعداد ساقه } \\
\text { No. Stem }\end{array}$ & $\begin{array}{l}\text { تعداد كره } \\
\text { No. Node }\end{array}$ & $\begin{array}{c}\text { برگs : } 1 \text { : ساقه : Stem } \\
\text { Leaf }\end{array}$ & زيست توده & $\begin{array}{c}\text { وزن خشك ريشه } \\
\text { Root dry weight }\end{array}$ & $\begin{array}{l}\text { بخش قابل برداشت:غيرقابل برداشت } \\
\text { Harvestable: Non-Harvestable }\end{array}$ \\
\hline Regrowth height & ارتفاع رشد مجدد & & $-0.245^{* *}$ & $0.430^{* *}$ & $0.278^{* * *}$ & $0.275^{* *}$ & $0.156^{*}$ & 0.116 \\
\hline No. Stem & تعداد ساقه & & & -0.016 & $-0.382^{* * *}$ & $0.426^{* *}$ & -0.033 & $0.319^{* *}$ \\
\hline Leaf:Stem & بر گك:ساقه & & & & & $-0.150^{*}$ & -0.006 & $-0.140^{*}$ \\
\hline Biomass & زيست توده & & & & & & $0.651^{* *}$ & 0.052 \\
\hline Root dry weight & وززن خشك ريشه & & & & & & & $-0.632^{* *}$ \\
\hline
\end{tabular}


عملكرد جين را نسبت به تيمار آبيارى كامل كاهش داد

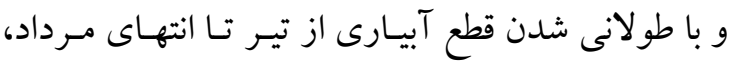

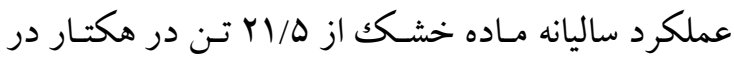

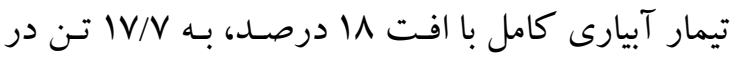

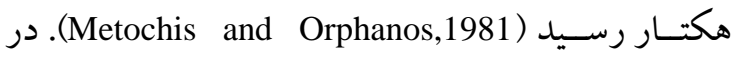

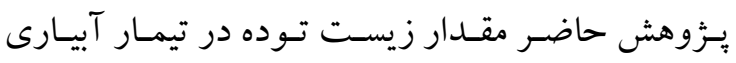

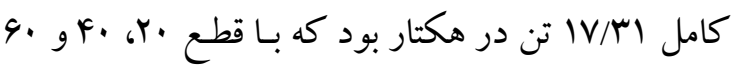

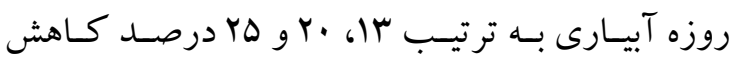

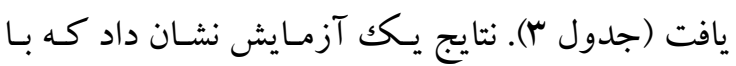

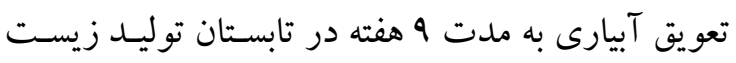

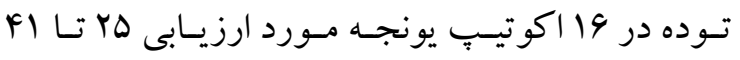
درصد كاهش داشت (Bouizgaren et al., 2010). نتايج يـك آزمـايش در خصـوص قطـع آبيـارى در يونجسه

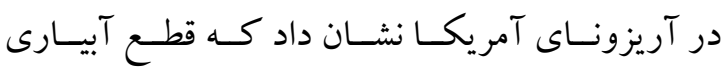

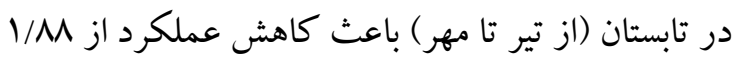

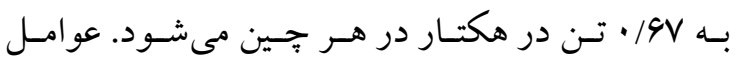

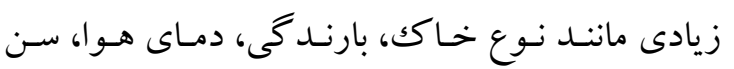

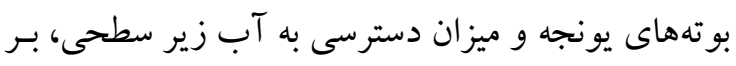

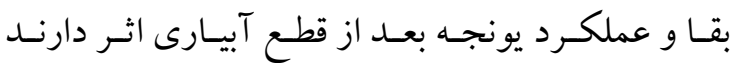

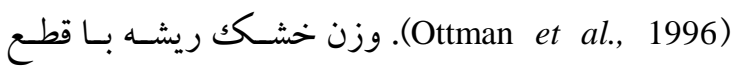
آبيارى طى ·r روز كاهش نسبى يافت و در تيمـار قطع

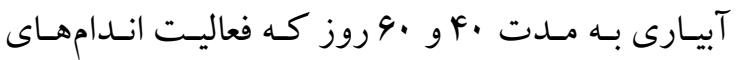

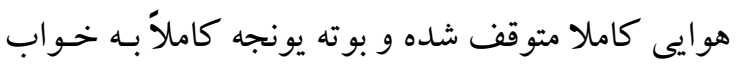

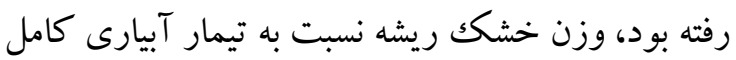
به ترتيـب و و ها درصـد افز ايش نشـان داد (جـدول سم).

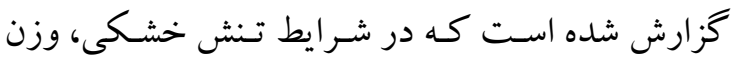
خشـك ريشـه در ارقـام يونجـه داراى خـواب، بيشـتر از ارقـام بـدون خـواب اسـت (Hattendorf et al., 1990).

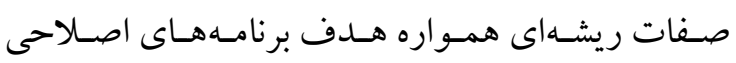

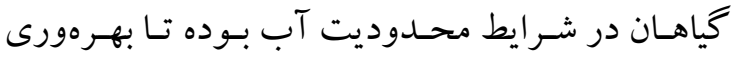

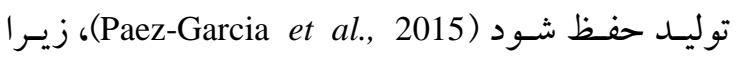

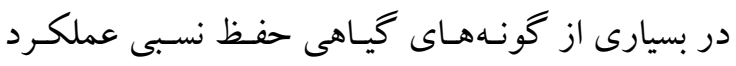

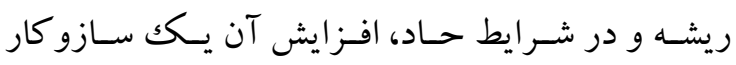

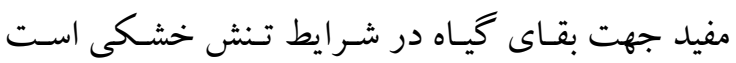

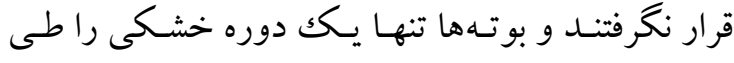

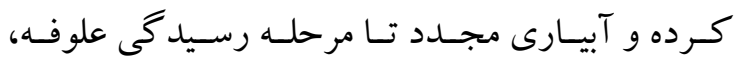
از سر گرفته شد، در نتيجه در تيمارهـاى قطع آبيـارى و و

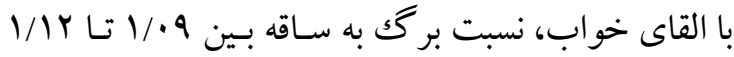

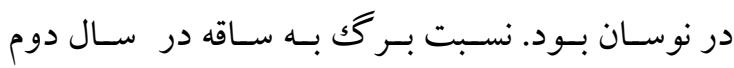

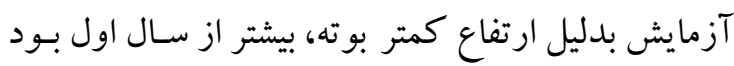

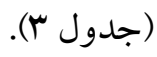
بالاترين نسبت بـرك بـه سـاقه در كل آزمايش در

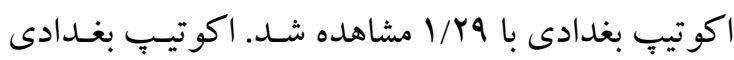

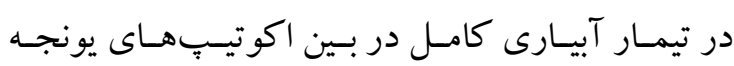

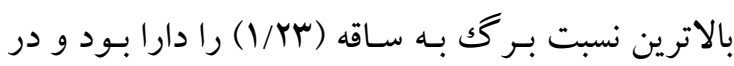

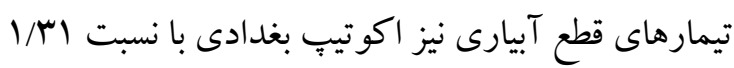

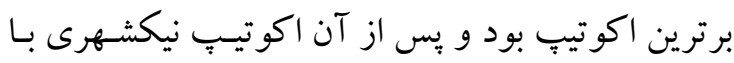

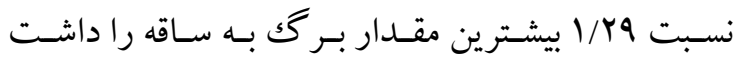

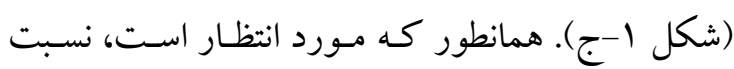

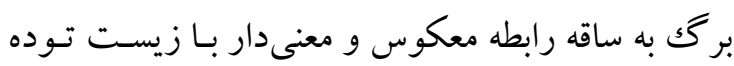

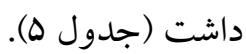

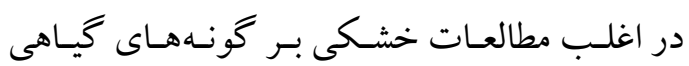
يكساله و نحوه حفـظ رشـد و عملكـرد آنها در شـرايط

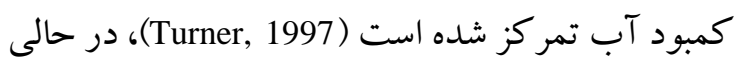

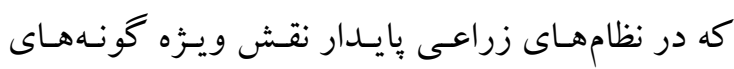

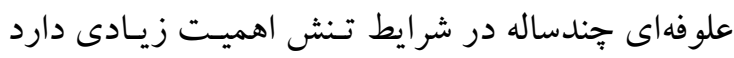
(Ridley et al., 1997)

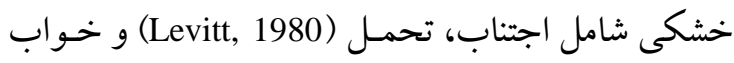

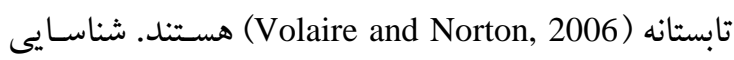
نحوه تسهيم زيست توده و انتخاب اكوتيـبِهـاى يونجـهـ

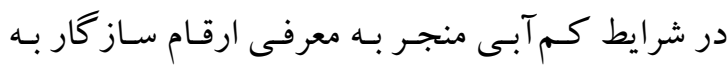
شـر ايط خشكى شـــــ اسـت (Annicchiarico, 2007). كرم شدن هوا در تابستان باعث كاهش عملكـرد يونجـه

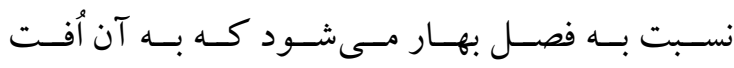

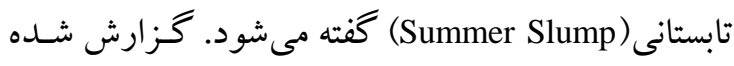

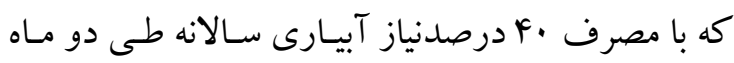

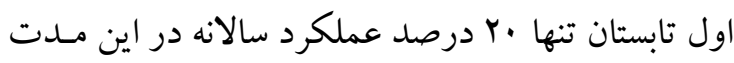

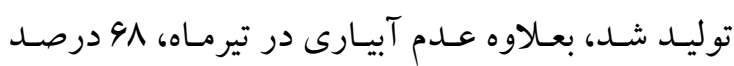




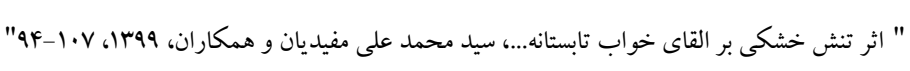
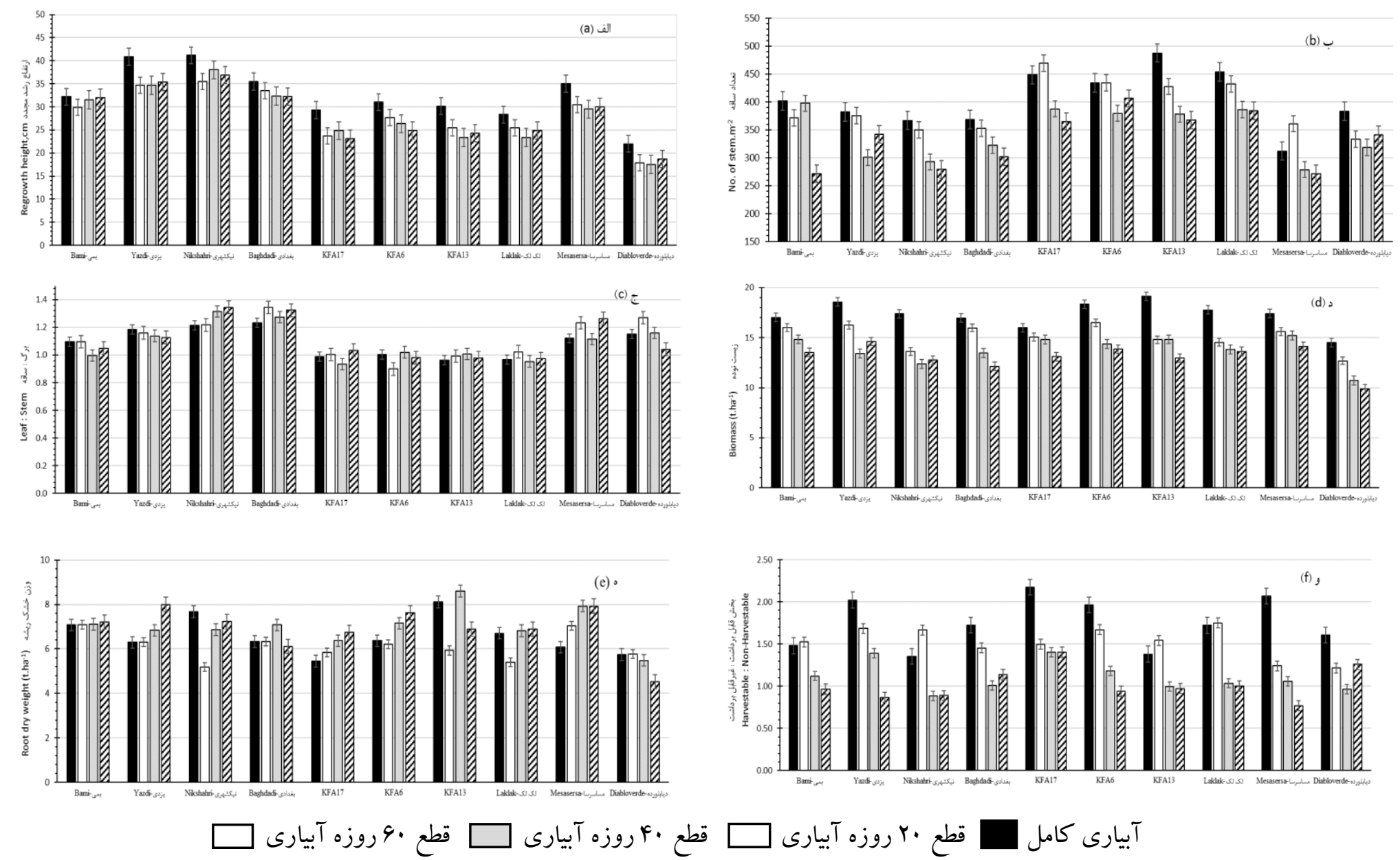

قطع ·r روزه آبيارى $\square$

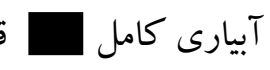

Full irrigation

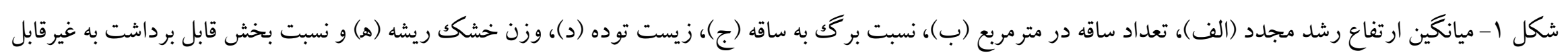

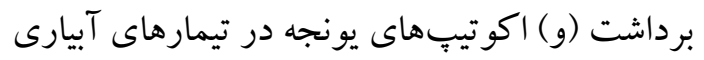

Fig. 1. Mean of Regrowth Height (a), No. of Stem.m ${ }^{-2}$ (b), Leaf : Stem (c), Biomass (d), Root dry weight (e), and Harvestable : Non-Harvestable (f) of alfalfa ecotypes in irrigation treatments 


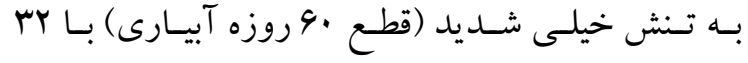

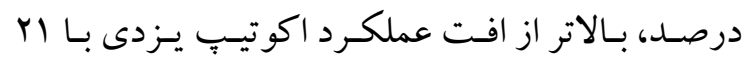

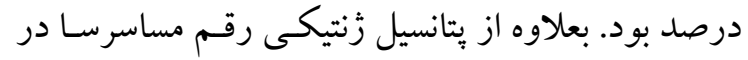

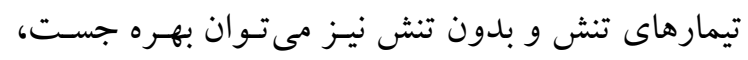

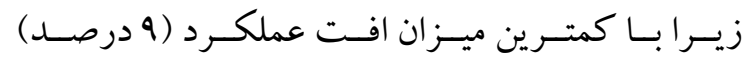

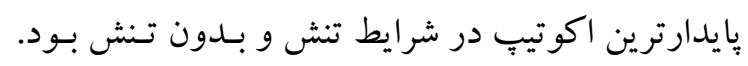

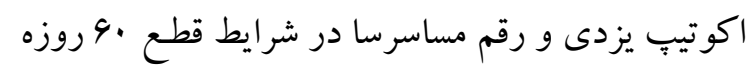

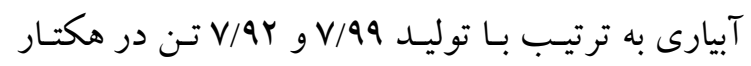

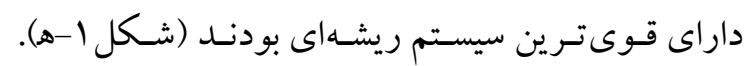

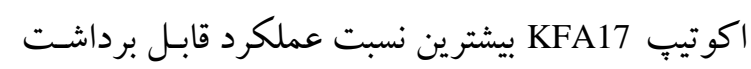

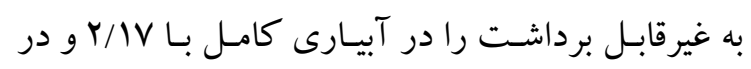

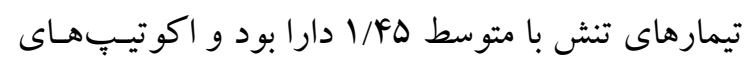
يزدى و KFA6 از اين نظر در جايگًاهــاى بعـدى قرار داشتند (شكل ا-و ).

\section{نتيجه كيرى}

نتايج اين آزمايش نشـان داد كه در شـرايط آبيـارى

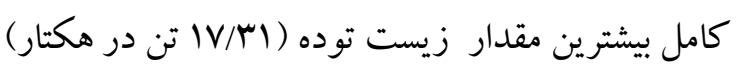

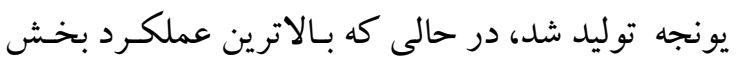

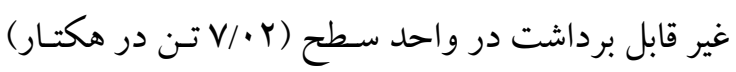

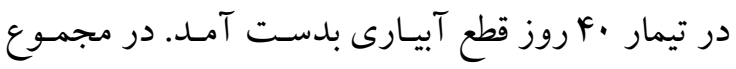

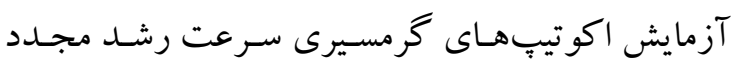
بالاترى نسبت بـه اكوتيـهـهـاى سردسيرى داشـتند، در

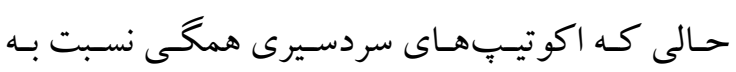

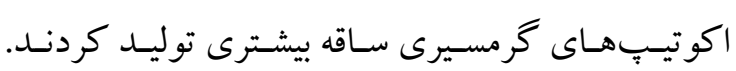

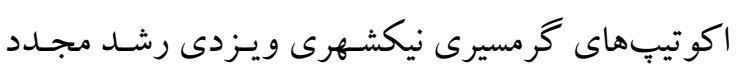

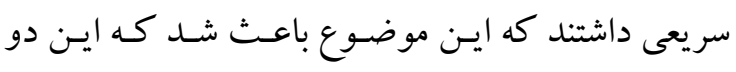

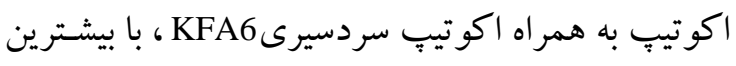

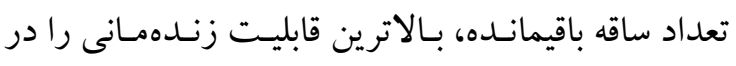
شر ايط قطع آبيارى و القاى خواب نشان دهنــ. بـالاترين

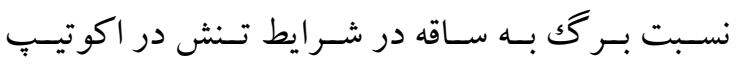
كرمسيرى بغدادى و نيكشهرى و در شر ايط بـدون تسنش

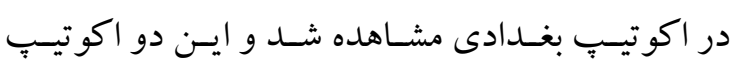
بالاترين كيفيت علوفه را در شرايط آزمايش داشـتند. در مر دور
(Lynch, 2007). نسبت بخش قابل برداشـت بـه غيرقابـل

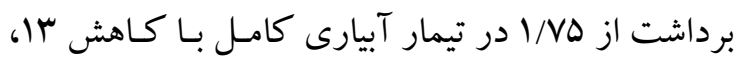

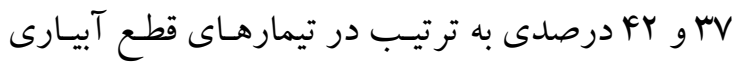

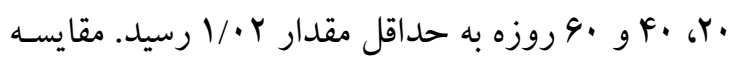

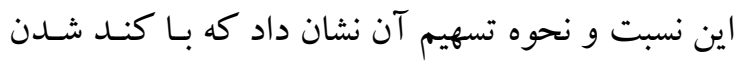

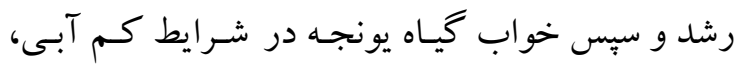

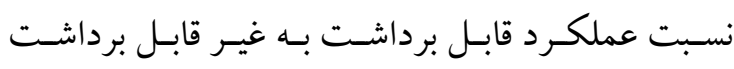

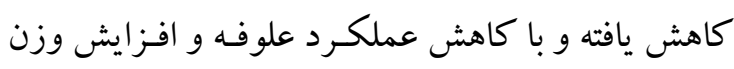

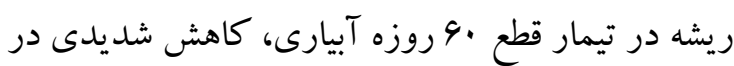
توليد علوفه قابل برداشت اين تيمار بوجود آمد. در بين اكوتيبهاى يونجه مـورد ارزيسابى، اكوتيسب

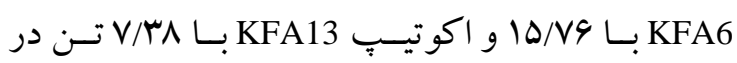

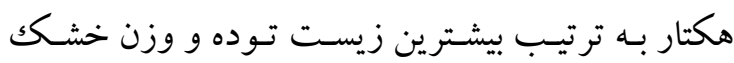
ريشه را در مجموع تيمارهاى آزمايشى داشت. بـه دنبـال

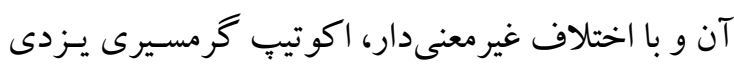

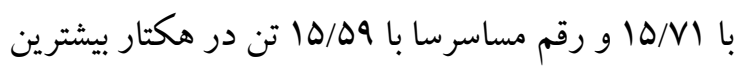

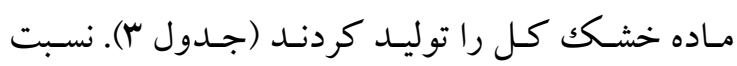

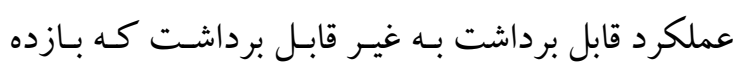

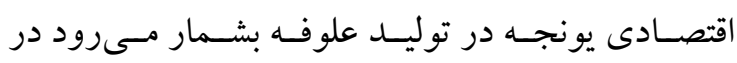

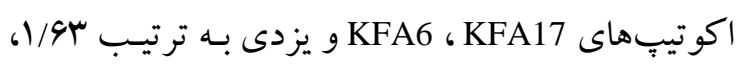

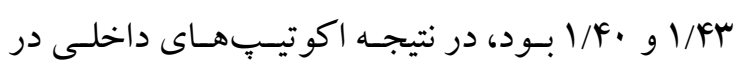

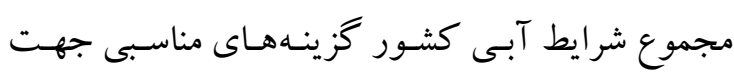

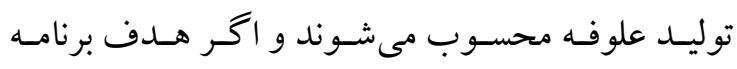

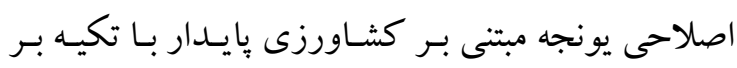

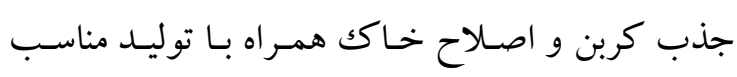
علوفه باشد، مى توان از رقم خـارجى مساسرسـا در كنـار

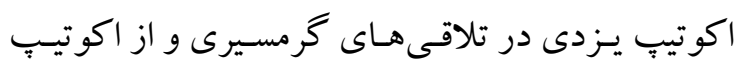

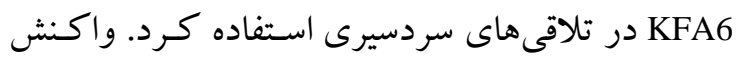

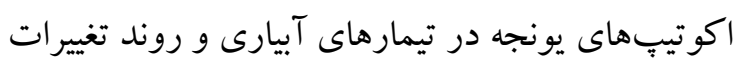

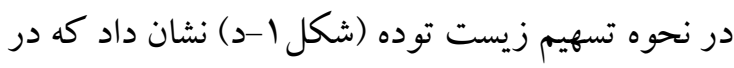

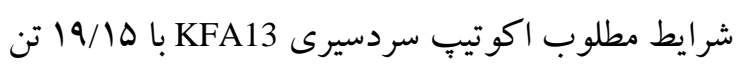

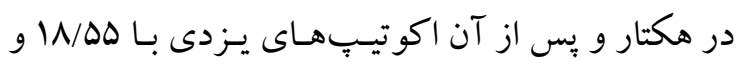

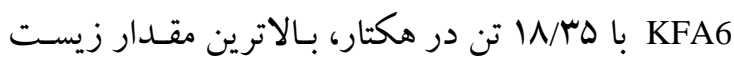

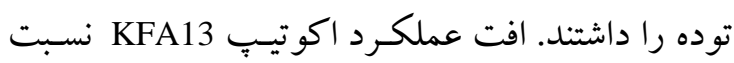




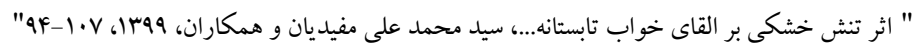

$$
\begin{aligned}
& \text { KFA17 برترى نسبى دارد. در مجموع شر ايط از يتانسيل } \\
& \text { مجموع آزمايش، اكوتيسب گرمسيرى يـزدى، اكوتيسب }
\end{aligned}
$$

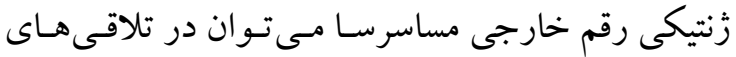

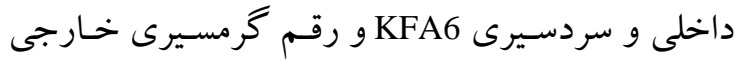

$$
\begin{aligned}
& \text { يونجه جهت بهبود عملكرد زيست توده استفاده كرد. }
\end{aligned}
$$

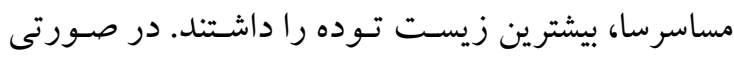

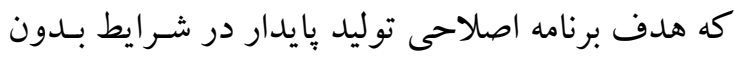

$$
\begin{aligned}
& \text { سياسگز ارى }
\end{aligned}
$$

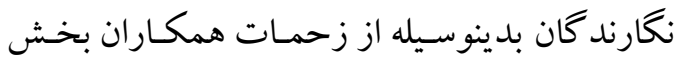

$$
\begin{aligned}
& \text { تنش و تنش باشد، به نحوى كه عملكرد علوفه به همـر اه }
\end{aligned}
$$

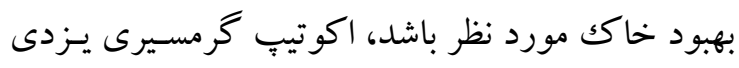

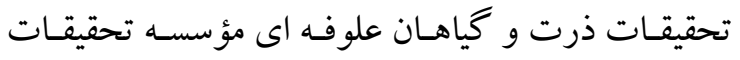

$$
\begin{aligned}
& \text { كزينه مناسبى به نظر مىرسد. در مناطق سردسيرى ايسن }
\end{aligned}
$$

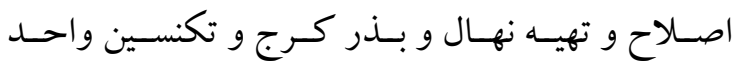

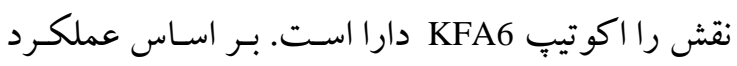

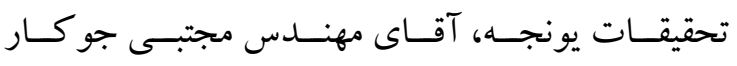

$$
\begin{aligned}
& \text { سباسگز ارى مى كنند. }
\end{aligned}
$$

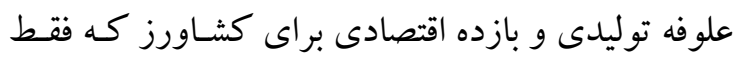

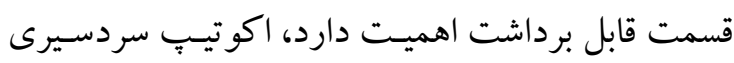

\section{References}

منابع مورد استفاده

Annicchiarico, P. 2007. Lucerne shoot and root traits associated with adaptation to favorable or drought-stress environments and to contrasting soil types. Field Crops Res. 102: 51-59.

Annicchiarico, P., L. Pecetti and A. Tava. 2013. Physiological and morphological traits associated with adaptation of lucerne (Medicago sativa) to severely drought-stressed and to irrigated environments. Ann. Appl. Biol. 162: 27-40.

Bolinder, M. A., D. A. Angers, G. Bélanger, R. Michaud and M. R. Laverdière. 2002. Root biomass and shoot to root ratios of perennial forage crops in eastern Canada. Cana. J. Plant Sci. 82: 731-737.

Brouwer, D. J., S. H. Duke and T. C. Osborn. 2000. Mapping genetic factors associated with winter hardiness, fall growth and freezing injury in autotetraploid alfalfa. Crop Sci. 40: 1387-1396.

Brummer, E. C., M. M. Shah and D. Luth. 2000. Reexamining the relationship between fall dormancy and winter hardiness in alfalfa. Crop Sci. 40: 971-977.

Bouizgaren, A., R. Kallida and C. Alfaiz. 2010. Evaluation of drought tolerance variability in Mediterranean alfalfa cultivars in the field under Moroccan conditions. Sustain. Use Genet. Diversity Forage Turf Breed. 4: 283-287.

Doorenbos, J. and A. K. Kassam. 1979. Yield response to water. Irrigation and Drainage No. 33. FAO, United Nations, Rome, Italy.

Erice, G., S. Louahlia, J. J. Irigoyen, M. Sanchez-Diaz and J. C. Avice. 2010. Biomass partitioning, morphology and water status of four alfalfa genotypes submitted to progressive drought and subsequent recovery. J. Plant Physiol. 167: 114-120.

Eziz, A., Z. Yan, D. Tian, W. Han, Z. Tang and J. Fang. 2017. Drought effect on plant biomass allocation: A meta-analysis. Ecol. Evol. 7: 11002-1110.

Hattendorf, M. J., D. Evans, R. Wand and N. Peaden. 1990. Canopy temperature and stomatal conductance 


$$
\text { "نشريه علوم زراعى ايران"، جلد بيست و دوم، شماره ا، بهار 94ها }
$$

of water stressed dormant and non-dormant alfalfa types. Agro. J. 82: 873-877.

Hsiao, T. C. and E. Acevedo. 1974. Plant response to water deficits, water use efficiency and drought resistant. Agric. Meteor. 14: 56-84.

Hufnagel, B., S. M. de Sousa, L. Assis, C. T. Guimaraes, W. Leiser, G. C. Azevedo, B. Negri, B. G. Larson, J. E. Shaff and M. M. Pastina. 2014. Duplicate and conquer: multiple homologs of PHOSPHORUSSTARVATION TOLERANCE1enhance phosphorus acquisition and sorghum performance on Low-P soils. Plant Physiol. 166: 659-677.

Kell, D. B. 2011. Breeding crop plants with deep roots: Their role in sustainable carbon, nutrient and water sequestration. Ann. Bot. 108(3): 407-418.

Leach, G. J. 1970. Shoot growth on lucerne plants cut at different height. Aust. J. Agric Res. 21: 586-591.

Levitt, J. 1980. Response of plant to environmental stress, Academic Press, New York, USA.

Li, F. R., C. Gao, H. L. Zhao and X. Li. 2002. Soil conservation effectiveness and energy efficiency of alternative rotations and continuous wheat cropping in the Loess plateu of northwest China. Agric. Ecosys. Environ. 91: 101-111.

Lynch, J. P. 2007. Roots of the second green revolution. Turner review No. 14. Aust. J. Bot. 55: 493-512.

Marquez-Ortiz, J. J., L. D. Johnson, D. K. Barnes and D. H. Basigalup. 1996. Crown morphology relationships among alfalfa plant introductions and cultivars. Crop Sci. 36: 766-770.

Mc Williams, D. 2002. Drought Strategies for Alfalfa. Report of Department of Extension Plant Sciences, New Mexico State University, Las Cruces, New Mexico.

Metochis, Chr. and P. I. Orphanos. 1981. Alfalfa yield and water use when forced into dormancy by withholding water during the summer. Agron. J. 73(6): 1048-1050.

Moore, J. E. and D. J. Undersander. 2002. Relative forage quality, an alternative to relative feed value and quality index. Proceeding $13^{\text {th }}$ Annual Florida Ruminant Nutrition Symposium, 10-11 January, Florida, USA.

Norton, M., F. Volaire, F. Lelievre and S. Fukai. 2009. Identification and measurement of summer dormancy in temperate perennial grasses. Crop Sci. 49: 2347-2352.

Ottman, M., B. R. Tickes and R. L. Roth. 1996. Alfalfa yield and stand response to irrigation termination in an arid environment. Agron. J. 88(1): 44-48.

Paez-Garcia, A., C. M. Motes, W. Scheible, R. Chen, E. B. Blancaflor and M. J. Monteros. 2015. Root traits and phenotyping strategies for plant improvement. Plants. 4(2): 334-355.

Ridley, A. M., R. E. White, R. J. Simpson and L. Callinan. 1997. Water use and drainage in phalaris, cocksfoot and annual ryegrass pastures. Aust. J. Agric. Res. 48: 1011-1023.

Shewmaker, G. E. and R. Thaemert. 2004. Measuring moisture in hay. In: Proceedings, $34^{\text {th }}$ California Alfalfa Symposium, 13-5 December, San Diego, CA. USA. 


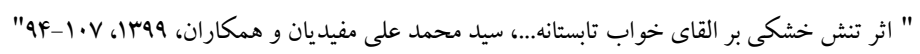

Schonhorst, M. H., R. K. Thompson and R. E. Dennis. 1963. Does it pay to irrigate alfalfa in the summer? Progress. Agric. Arizona. 15(6): 8 -9.

Turner, N. C. 1997. Further progress in crop water relations. Adv. Agron. 58: 293-338.

Turner, N. C. 1986. Crop water deficits: a decade of progress. Adv. Agron. 39: 1-51.

Uga, Y., K. Sugimoto, S. Ogawa, J. Rane, M. Ishitani, N. Hara, Y. Kitomi, Y. Inukai, K. Ono and N. Kanno. 2013. Control of root system architecture by DEEPER ROOTING1 increases rice yield under drought conditions. Nat. Genet. 45: 1097-1102.

Volaire, F. and M. Norton. 2006. Summer dormancy in temperate perennial grasses. Annu. Bot. (Lond), 98 : 927-933.

Volenec, J. 2010. Winter versus summer dormancy: Alfalfa fall dormancy. Report of Department of Agronomy, Purdue University, West Lafayette, USA. 
"نشريه علوم زراعى ايران"، جلد بيست و دوم، شماره ا، بهار 199"

\title{
Effect of drought stress on the induction of summer dormancy and dry matter partitioning in alfalfa (Medicago sativa $\mathrm{L}_{\text {.) }}$ ecotypes
}

\author{
Mofidian, S. M. A., ${ }^{1}$ J. Ahmadi ${ }^{2}$ and A. Moghaddam ${ }^{3}$
}

\begin{abstract}
Mofidian, S. M. A., J. Ahmadi and A. Moghaddam. 2020. Effect of drought stress on the induction of summer dormancy and dry matter partitioning in alfalfa (Medicago sativa L.) ecotypes. Iranian Journal of Crop Sciences. 22(1): 94-107. (In Persian).
\end{abstract}

Study of potential of alfalfa ecotypes in biomass partitioning and harvestable and non-harvestable parts as well as induction of summer dormancy under water scarcity can lead to develop adapted cultivars for sustainable farming system andto meet targets of the breeding program. Therefore, this experiment was conducted with 10 alfalfa ecotypes under four irrigation managements at Seed and Plant Improvement Institute (SPII), Karaj, Iran, during 2016-2018. The irrigation treatments included; full irrigation and irrigation withhold for 20, 40 and 60 days. Under stress and on stress conditions, Nikshahri and Yazdi ecotypes had the highest regrowth rate, therefore, these two ecotypes as well as KFA6 ecotype with high stem number demonstrated the highest survival rate under induction of summer dormancy. The highest biomass belonged to normal irrigation with 17.31 t.ha ${ }^{-1}$ while the maximum unharvestable part yield with 7.02 t.ha- ${ }^{-1}$ was measured in irrigation withhold treatment for 40 days. Yazdi and KFA6 ecotypes showed the maximum total biomass (15.71 and 15.76 t.ha $^{-1}$ respectively) among warm and cold region ecotypes with different fall dormancy scores and can be used as aprentsin alfalfa breeding programs. Regarding to biomass partitioning ratio, KFA17, KFA6 and Yazdi, which are landraces, had greater harvestable part to unharvestable part ratio with 1.63, 1.43 and 1.40, respectively. Therefore, these landraces can be selected for forage production under different irrigation managements. As the leaf to stem ratio has the main role in forage quality, Baghdadi ecotype with leaf: stem ratio of 1.29 had the highest forage quality among studied ecotypes. Baghdadi also maintained its high quality in all irrigation management treatments. In alfalfa breeding programs focused on improvement of forage and unharvestable yield for sustainable production in both optimum and stress environment conditions, Yazdi and KFA6 ecotypes seems to be suitable.

Key words: Alfalfa, Forage yield, Irrigation, Leaf: stem ratio and Regrowth.

Received: August, 2019 Accepted: December, 2019

1. PhD Student, Imam Khomeini International University, Qazvin, Iran and Faculty Member of Seed and Plant Improvement Institute, Agricultural Research, Education and Extension Organization (AREEO), Karaj, Iran (Corresponding author) (Email: amofidian@ymail.com)

2. Professor, Imam Khomeini International University, Qazvin, Iran

3. Assistant Prof., Seed and plant Improvement Institute, Agricultural Research, Education and Extension Organization (AREEO), Karaj, Iran 